\title{
Sonographic Patterns of Retained Products of Conception Among Women Attending Murtala Muhammed Specialist Hospital Kano, Nigeria
}

\author{
*Abubakar Aminu Abubakar', Mohammed Sidi', \\ Umar Mansur ${ }^{1}$, Anas Ya' ${ }^{1}$, \\ Aliyu Abdullahi Hassan ${ }^{2}$, Khadijah Aliyu Sadiq ${ }^{1}$ \\ ${ }^{1}$ Department of Medical Radiography, \\ Faculty of Allied Health Sciences, \\ College of Health Sciences, \\ Bayero University, Kano. \\ ${ }^{2}$ Radiology Department, \\ Aminu Kano Teaching Hospital.
}

E-mail: sadiqbabahabu@gmail.com

\begin{abstract}
Retain products of conception (RPOC) remains a major concern because its complications are among the leading cause of morbidity and mortality among women with postpartum uterus. Every locality should have a documented findings of postpartum uterus predicting retained products of conception. This study was aimed at evaluating the sonographic pattern of RPOC among women attending Murtala Muhammad Specialist Hospital, Kano. The study was prospective, conducted from January 2021 to August 2021. A total of 200 patients referred on the suspicion of RPOC on the basis of history or clinical examination were enrolled in the study. Transabdominal ultrasound with $3.5 \mathrm{MHtz}$ transducer was performed in all referred cases. The findings obtained were recorded on data capture sheet. Data was analyzed using SPSS Version 23.0. Mean age of the patients was $21.7 \pm 6.7$ years and the mean gestational age was $11.7 \pm 4.8$ weeks. Most of the patients present with per vaginal bleeding, lower back pain or fever as their clinical history. Sonographic findings of RPOC were mix-echogenic content 106(53\%), hypoechoic fluid collection 52(26\%) and hyperechoic mass 42 (21\%). The correlation between clinical history and sonographic pattern of RPOC shows a significant weak positive correlation ( $r=0.15$ and $p=0.03$ ). The correlation between RPOC size and gestational age also shows a significant weak positive correlation $(r=0.27$ and $p=0.00)$. Sonography is an accurate tool for diagnosis of retained products of conception, with mixed echogenic content as the most common sonographic pattern RPOC.
\end{abstract}

Keywords: Sonography, RPOC, Mix-echogenicity, GA, Kano.

\section{INTRODUCTION}

Retained products of conception (RPOC) refers to intrauterine tissue that develops after conception and persists after surgical pregnancy termination, miscarriage, and vaginal or cesarean delivery (Antonella et al., 2015). RPOC has been described by some authors as non- 
villous trophoblastic tissue, chorionic villi or fetal membranes while others reported that RPOC consist of the gestational sac, the decidua capsularis, chorionic villi or the embryo itself (Hamerlynck et al., 2018). RPOC is suspected when a postpartum patient present with symptoms of hemorrhage, endometritis, lower abdominal or pelvic pain, vaginal discharge and fever (Adkins et al., 2016). However, RPOC may mimic the features of an arteriovenous malformation (AVM) and gestational trophoblastic disease (GTD), therefore differentiation of RPOC from AVM and GTD is very important in other to avoid misdiagnosis. The most common complication of RPOC is postpartum hemorrhage which occur as a result of subinvolution, infections and intra uterine adhesions (Weissbach et al., 2015).The standard treatment of RPOC is dilatation and curettage (D and C). However this intervention is not without risk, further complications can be seen such as uterine perforation, cervical laceration and may even lead to hysterectomy (Mulic-Lutvica et al., 2009). Ultrasound is a useful tool for diagnosing RPOC and is said to be more accurate than clinical investigation alone as it shows $44-85 \%$ sensitivity and a specificity of $88-94 \%$ (Thangarajah et al., 2019; Sellmyer et al., 2013). Therefore, in order to avoid unwanted surgical intervention which results in further complication ultrasound should be performed to confirm the diagnosis. The common sonographic patterns of RPOC includes endometrial thickness, mix-echogenic contents, hyperechoic material inside the cavity, or complex endometrial fluid. RPOC remains a major concern because its complications are among the leading cause of morbidity and mortality among women with postpartum uterus. Every locality should have a documented findings of postpartum uterus predicting retained products of conception. However, empirical study shows that the findings has not being documented in Kano metropolis. The findings of the study are expected to serve as a guide to the sonographer, sonologist, radiologist and physician in the management of RPOC. Thus the study aimed at evaluating the sonographic pattern of retained products of conception among women attending Murtala Muhammad Specialist Hospital Kano.

\section{MATERIALS AND METHODS}

The study was prospective and cross-sectional in nature conducted in Murtala Muhammad Specialist Hospital (MMSH), Kano State from January 2020 to August 2021. A consecutive sampling technique was employed to select 200 samples using Taro Yamani's formula for infinite population. All female patients referred to MMSH for ultrasound scan of the uterus with suspected cases of RPOC were involved in the study. An ethical clearance was sought and obtained from the Research and Ethics Committee of Kano State Ministry of Health prior to the commencement of data collection. Informed consent was obtained from each patient that was recruited for the study. Therefore, only patients that accepted to participate in the study were included. The ultrasonographic examination of the uterus was carried out on full bladder which would serves as a window for better visualization of the uterus. A transabdominal scan was performed using an ultrasound machine (Toshiba TA312 2010) equipped with a $3.5 \mathrm{MHz}$ curvilinear transducer. All patient laid supine on the table, the examiner stood at the right side of the patient. Ultrasound gel was applied on the hypogastric region, the transducer was placed at the midline of the body and just superior to and directly against the symphysis pubis to visualize the uterus. Sagittal and transverse planes were obtained, the size of the RPOC was recorded and the sonographic appearance was noted and documented in a data capture sheet. Both descriptive and inferential statistics were applied to the data. Means \pm standard deviations (SD) of the age and gestational age were presented using in a table. Sonographic findings and clinical history were presented in frequencies and percentages. The correlation between the clinical history and sonographic pattern of RPOC was determine with Spearman's correlation and Pearson's correlation coefficient was employed to determine the relationship between GA and sonographic 
pattern of RPOC. Data were analyzed using the statistical package for social sciences (SPSS) version 23 (SPSS Inc., Chicago, Illinois). Statistical significance was considered at $p<0.05$.

\section{RESULTS}

Results from the study revealed that the mean age of the participants was $27.1 \pm 6.7$ years and the mean gestational age was $11.7 \pm 4.8$ weeks (Table 1) while Table 2 showed that mixed echogenic content was the most frequent sonographic finding representing 106 (53\%). On the other hand, Table 3 revealed that per virginal bleeding and lower abdominal pain were the most frequent clinical history in patients with RPOC representing $56(28.0 \%)$.

Table 1: Mean and standard deviation of the age and gestational age.

\begin{tabular}{ll}
\hline Variables & Mean \pm SD \\
\hline Age (years) & $27.1 \pm 6.7$ \\
& $(18-48)$ \\
Gestational age (weeks) & $11.7 \pm 4.8$ \\
& $(6-30)$ \\
\hline
\end{tabular}

Table 2: Sonographic pattern of retained products of conception.

\begin{tabular}{lcl}
\hline Sonographic findings & Frequency & Percent \\
\hline Hyperechoic mass & 42 & 21.0 \\
Mixed echogenic content & 106 & 53.0 \\
Hypoechoic fluid collection & 52 & 26.0 \\
\hline Total & 200 & 100.0 \\
\hline
\end{tabular}

Table 3: Clinical History of the study population.

\begin{tabular}{lcc}
\hline Clinical History & Frequency & Percent \\
PVB, LAP,FEVER & 30 & 15 \\
PVB,LAP,LBP & 3 & 1.5 \\
PVB, FEVER & 49 & 24.5 \\
PVB,LAP & 56 & 28 \\
PVB, HEADACHE & 9 & 4.5 \\
PPH,PP,FEVER & 1 & 0.5 \\
PP,LAP & 1 & 0.5 \\
LAP,FEVER & 8 & 4.0 \\
LAP & 4 & 2.0 \\
PVB & 39 & 19.5 \\
Total & 200 & 100 \\
\hline Key: PVB: Per Vaginal Bleeding. LAP: Lower Abdominal Pain. PPH: Postpartum Hemorrhage. PP: Pelvic Pain. \\
LBP: Lower Back Pain.
\end{tabular}


Furthermore, Table 4 revealed a weak significant positive correlation between clinical history and sonographic pattern of RPOC while Table 5 revealed a weak significant positive correlation between RPOC size and sonographic pattern of RPOC.

Table 4. Correlation between clinical history and sonographic pattern of RPOC

\begin{tabular}{lc}
\hline $\begin{array}{l}\text { Spearman's correlation (r value }) \\
\text { Significance } \quad(p \text { value })\end{array}$ & 0.15 \\
\hline & 0.03 \\
Table.5: Correlation between RPOC Size and the Gestational Age \\
\hline Pearson's correlation ( $\mathrm{r}$ value ) & 0.27 \\
Significance $\quad(\mathrm{p}$ value $)$ & 0.00 \\
\hline
\end{tabular}

\section{DISCUSSION}

The findings of the current study show that the age of the patients ranged from 18-48 years with a mean age of $27.1 \pm 6.7$ years. Other studies reported similar findings such as the study of Iqbal et al. (2019), who reported a mean age of 30.8 3.9 years (19-41 years). Qazi et al. (2013) reported a mean age of $29.75 \pm 7.89$ years (14-44 years). The possible reason for the similarities could be related to the age brackets of the participants as they were all within the reproductive age. The mean gestational age of the participants in the current study was $11.7 \pm 4.8$ weeks (6-30 weeks). Matijevic et al. (2009) and Durfee et al. (2005) reported higher GA than the current study. Possible reasons could because only patients that delivered at third trimester were included by Matijevic et al. (2009) while Durfee et al. (2005), studied only patients that delivered in the second and third trimester, while the current study involved all the trimesters. In the current study, the most common sonographic pattern of RPOC was a mixed echogenic content representing 106(56\%), followed by hypoechoic mass representing $52(26 \%)$ and the least finding was hyperechoic mass accounted for $42(21 \%)$. Contrarily, the findings from Chopra et al. (2017) and Durfee et al. (2005) reported hyperechoic mass as the most sensitive predictor for RPOC. This contradiction might be due to the stage at which the pregnancy was terminated. This study showed that patients with suspected cases of RPOC presented with per vaginal bleeding, lower abdominal, lower back pain, pelvic pain, postpartum hemorrhage and fever, as their clinical history. However the most common clinical history were per vaginal bleeding and lower abdominal pain 56 $(28.0 \%)$. The findings are in agreement with the findings reported by Chopra et al. (2017) and Durfee et al. (2005). However, these findings are non-specific and may be similar to those following a normal delivery. The study further revealed a significant weak positive correlation between clinical findings and sonographic findings of RPOC, confirming that sonographic findings together with clinical findings provide an accurate diagnosis of RPOC which help in preventing an unnecessary surgical intervention. This findings are compatible with those of previous studies reported by Iqbal et al. (2019), Matijevic et al. (2009) and Durfee et al. (2005). However, Thangarajah et al. (2019) reported that endometrial mass and clinical symptoms were not predictors of RPOC but rather, patient's age as well as mode of delivery seem to be significant predictors of RPOC. The differences in results might be explained by the differences in the mean gestational age which was 37.6 weeks compared to that of the current study.

The current study shows a weak positive correlation between RPOC size and gestational age. However, RPOC size does not depend solely on gestational age because different individuals have different RPOC size irrespective of gestational age. 


\section{CONCLUSION}

Sonography is an accurate tool in the diagnosis of retained product of conception, with mixed echogenic content as the most common sonographic pattern of RPOC. Therefore, sonography should be performed in addition to clinical evaluation in other to avoid unnecessary surgical interventions which might result in further complications.

\section{REFERENCES}

Adkins, K., Minardi, J., Setzer, E., and Williams, D. (2016). Retained Products of Conception: An Atypical Presentation Diagnosed Immediately with Bedside Emergency Ultrasound. Case Reports in Emergency Medicine, 2016, 1-3. https:/ / doi.org/10.1155/2016/9124967

Antonella, G., Luisa, D. B., Chiara, A., Alessandra, R., and Caserta, D. (2015). Conservative and timely treatment in retained products of conception: A case report of placenta accreta ritention. International Journal of Clinical and Experimental Pathology, 8(10), 13625-13629.

Chopra, N., Kaur, M., and Mohi, M. K. (2017). Correlation of ultrasound with histopathology for retained products of conception in medically managed abortions. International Journal of Reproduction, Contraception, Obstetrics and Gynecology, 6(8), 3372. https:/ / doi.org/10.18203/2320-1770.ijrcog20173373

Durfee, S. M., Frates, M. C., Luong, A., and Benson, C. B. (2005). The sonographic and color Doppler features of retained products of conception. Journal of Ultrasound in Medicine, 24(9), 1181-1186. https:// doi.org/10.7863/jum.2005.24.9.1181

Hamerlynck, T. W., Meyers, D., Van der Veken, H., Bosteels, J., and Weyers, S. (2018). Fertility outcome after treatment of retained products of conception: a systematic review. Gynecological Surgery, 15(1), 1-7. https://doi.org/10.1186/s10397-018-1044-6

Iqbal, K., Manzoor, S., Butt, R. W., Niazi, M., Kulsoom, U., et al. (2019). Diagnostic Accuracy of Endovaginal Scan in Detection of Retained Products of Conception after Incomplete Abortion. Journal of Rawalpindi Medical College, 23(2), 93-96.

Matijevic, R., Knezevic, M., Grgic, O., and Zlodi-Hrsak, L. (2009). Diagnostic accuracy of sonographic and clinical parameters in the prediction of retained products of conception. Journal of Ultrasound in Medicine, 28(3), 295-299. https:/ / doi.org/10.7863/jum.2009.28.3.295

Mulic-Lutvica, A., Eurenius, K., and Axelsson, O. (2009). Uterine artery Doppler ultrasound in postpartum women with retained placental tissue. Acta Obstetricia et Gynecologica Scandinavica, 88(6), 724-728. https://doi.org/10.1080/00016340902934670

Qazi, A. S., Sami, S., and Akhtar, S. (2013). Diagnostic accuracy of transvaginal ultrasound in clinically suspected cases of retained products of conception. Pakistan Postgraduate Medical Journal. 24(1), 17-21.

Sellmyer, M. A., Desser, T. S., Maturen, K. E., Jeffrey, R. B., and Kamaya, A. (2013). Physiologic, histologic, and imaging features of retained products of conception. Radiographics, 33(3), 781-796. https:// doi.org/10.1148/rg.333125177

Thangarajah, F., Brunner, M., Pahmeyer, C., Radosa, J. C., Eichler, C., et al. (2019). Predictors of postpartal retained products of conception. In Vivo, 33(2), 469-472. https://doi.org/10.21873/invivo.11496

Weissbach, T., Haikin-Herzberger, E., Bacci-Hugger, K., Shechter-Maor, G., Fejgin, M., et al. (2015). Immediate postpartum ultrasound evaluation for suspected retained placental tissue in patients undergoing manual removal of placenta. European Journal of Obstetrics and Gynecology and Reproductive Biology, 192, 37-40. https:/ / doi.org/10.1016/j.ejogrb.2015.06.004 